\title{
Pastores, ovelhas desgarradas e as disputas pelo rebanho: Sobre a transcrucificação na Parada do orgulho LGBT de São Paulo em 2015
}

Shepherds, Lost Sheep and Disputes over the Flock: Trans-Crucifixion at the São Paulo LGBT Pride Parade, 2015

Bergers, brebis égarées et les disputes à cause du troupeau: sur la transcrucifixion durant la Marche des fiertés (Gay pride) LGBT de São Paulo en 2015

Rodrigo Otávio Moretti-Pires, Zeno Carlos Tesser Júnior, Marcelo Vieira e Murilo dos Santos Moscheta

\section{OpenEdition} Journals

Edição electrónica

URL: http://journals.openedition.org/rccs/6392

DOI: $10.4000 /$ rccs.6392

ISSN: 2182-7435

Editora

Centro de Estudos Sociais da Universidade de Coimbra

Edição impressa

Data de publição: 1 Setembro 2016

Paginação: 99-116

ISSN: 0254-1106

\section{Refêrencia eletrónica}

Rodrigo Otávio Moretti-Pires, Zeno Carlos Tesser Júnior, Marcelo Vieira e Murilo dos Santos Moscheta , «Pastores, ovelhas desgarradas e as disputas pelo rebanho: Sobre a transcrucificação na Parada do orgulho LGBT de São Paulo em 2015 », Revista Crítica de Ciências Sociais [Online], 110 | 2016, colocado online no dia 26 setembro 2016, criado a 21 abril 2019. URL : http://journals.openedition.org/ rccs/6392; DOI : 10.4000/rccs.6392 


\title{
RODRIGO OTÁVIO MORETTI-PIRES, ZENO CARLOS TESSER JÚNIOR, MARCELO VIEIRA, MURILO DOS SANTOS MOSCHETA
}

\section{Pastores, ovelhas desgarradas e as disputas pelo rebanho: Sobre a transcrucificação na Parada do orgulho LGBT de São Paulo em 2015}

\begin{abstract}
A Parada do orgulho LGBT de São Paulo (Brasil) é um dos maiores eventos mundiais da temática. Em julho de 2015 ocorreu a 19. ${ }^{a}$ edição do evento, e duas manifestações destacaram-se nos meios de comunicação em massa: uma travesti crucificada denunciando as fobias de gênero e violências contra pessoas LGBT, e um grupo de cristãos organizados sob o slogan "Jesus cura a homofobia". Essas expressões promoveram debates e disputas políticas importantes, uma vez que o combate aos direitos civis de pessoas LGBT é uma importante pauta dos políticos evangélicos brasileiros que compõem uma das mais importantes representações políticas na Câmara Federal de Deputados: a bancada evangélica. O presente artigo discute as disputas envolvidas no campo de gênero e suas implicações políticas perante as repercussões da 19. ${ }^{a}$ Parada do orgulho LGBT de São Paulo, utilizando-se dos aportes da teoria social de Pierre Bourdieu.
\end{abstract}

Palavras-chave: diversidade sexual; gênero; homofobia; movimento LGBT; política; religião.

\section{Introdução}

Manifestações que demarcam que a heterossexualidade é compulsória, tais como a Parada do orgulho $\mathrm{LGBT}^{1}$ da cidade de São Paulo (Brasil), ${ }^{2}$ despertam reações muitas vezes contraditórias dentro dos grupos sociais

\footnotetext{
${ }^{1}$ Conforme Natividade e Oliveira (2013), os movimentos sociais brasileiros passaram a utilizar a sigla LGBT (lésbicas, gays, bissexuais, travestis e transexuais) na luta por direitos e cidadania das minorias sexuais a partir da 1. ${ }^{a}$ Conferência Nacional LGBT, em 2008. Nos meios de comunicação em massa, assim como nos documentos oficiais do Estado brasileiro, também é a sigla utilizada para tratar de diversidade sexual e gênero.

${ }^{2}$ O evento ocorre anualmente desde 1997 nesse município.
} 
brasileiros, reafirmando conflitos, estabelecendo novas relações de competições por posições e legitimidade, assim como a dissolução de laços e o estabelecimento de outros. Tanto internamente, no próprio movimento, como na sociedade brasileira, as Paradas do orgulho LGBT são, ao mesmo tempo, espaços de luta e de conformação, a exemplo da apropriação financeira desses eventos pelo mercado do turismo. Assim, a própria parada é campo de disputas e sua potência disruptiva tem sido silenciada, apropriada, colonizada ao longo dos anos pelos dispositivos hegemônicos de dominação.

Em sete de julho de 2015, na cidade de São Paulo (Brasil), ocorreu a 19. ${ }^{a}$ Parada do orgulho LGBT, ${ }^{3}$ importante iniciativa de movimentos sociais com tom de denúncia e luta pelos direitos da minoria LGBT. Segundo Carvalho (2013), o crescimento numérico dos participantes do evento no transcorrer de suas diversas edições assim como em destaque nos meios de comunicação em massa, transformaram as Paradas do orgulho LGBT de São Paulo em um dos maiores eventos mundiais nessa categoria, com grande proeminência enquanto uma festividade que atrai milhares de pessoas. De qualquer forma, trata-se de um importante marco político que traz ao público as discussões sobre os direitos LGBT no Brasil, sendo foco de apoio e reprovações, com tensões internas no movimento social, assim como reações, especialmente dos setores políticos vinculados a segmentos religiosos no país.

Na referida 19. ${ }^{a}$ Parada, entre 18 carros de som utilizados, uma ação que ocorreu em um deles foi alvo, nos dias que se seguiram, de divulgação maciça na mídia e de ataques de seguimentos políticos evangélicos, representados por figuras públicas como o Deputado Marco Feliciano, que também é pastor. Tratou-se da performance artística de Viviany Beleboni, ${ }^{4}$ no primeiro carro de som, que provocou tamanha hostilização à atriz que esta chegou a receber ameaças de morte.

$\mathrm{Na}$ referida performance, a travesti ${ }^{5}$ representou as agressões que diz ter vivenciado e presenciado entre seus amigos por meio de maquiagem.

\footnotetext{
${ }^{3}$ Doravante grafada como 19. ${ }^{a}$ Parada.

${ }^{4}$ Carolina Dantas (2015), “'Representei a dor que sentimos', diz transexual 'crucificada' na Parada Gay”. Portal G1 São Paulo, 08.06.2015. Consultado a 20.06.015, em http://g1.globo.com/ sao-paulo/noticia/2015/06/representei-dor-que-sentimos-diz-transexual-crucificada-na-parada-gay.html. UOL, "Transexual 'crucificada' na Parada Gay de SP diz ter sido ameaçada de morte". Consultado a 20.06.2015, em http://noticias.uol.com.br/cotidiano/ultimas-noticias/2015/06/08/ transexual-crucificada-na-parada-gay-de-sp-diz-ter-sido-ameacada-de-morte.htm.

5 Conforme identidade de gênero declarada em entrevista ao Coletivo "Adão e Ivo" (2015), "Entrevista com Viviany Belevoni - Transexual crucificada na Parada LGBT de SP". Consultado a 20.06.2015, em https://www.youtube.com/watch?v=g06xI74vd_4.
} 
Utilizou-se da figura da crucificação para denunciar a cotidiana violência impetrada contra travestis, transexuais e transgênero na sociedade brasileira. No alto da cruz utilizada, havia uma placa dizendo "Basta de homofobia com LGBT".

Outro coletivo também participou da 19. ${ }^{a}$ Parada, com enfoque diferente da performance da atriz mas de conteúdo de denúncia, utilizando-se do lema "Jesus cura homofobia" ${ }^{6}$ Com certo caráter performático, o grupo composto por pastores e fiéis evangélicos marchou com roupas brancas e cartazes. Nas frases, o movimento defendeu a coerência em relação ao princípio da paz como fundamento da religião cristã, o rompimento com o ódio, e iniciativas de amor ao próximo e a defesa dos oprimidos, conforme expresso no texto bíblico segundo os integrantes do grupo. No manifesto publicado ${ }^{7}$ em 07.06.2015 houve um ataque frontal aos líderes religiosos, inclusive com o uso da expressão "ideologias fundamentalistas" para caracterizá-los, na medida em que, segundo o grupo, se valem da homofobia e da cultura do medo da diferença para ferirem os princípios que o grupo apresenta como coerentes com a religião, além da incitação de crimes homofóbicos.

O Brasil é um país cristão, com predomínio da religião católica. No entanto, a porcentagem de cristãos evangélicos aumentou expressivamente em vinte anos. O censo populacional de 1991 apontou que esse seguimento religioso representava $9 \%$ da população brasileira, enquanto, no censo de 2010, houve o crescimento para 22,2\% da população (Instituto Brasileiro de Geografia e Estatística, 2012).

Giumbelli (2014) aponta que, no Brasil, os movimentos evangélicos apresentaram mudanças na forma de inserção social nas três últimas décadas do século Xx, com crescente utilização dos meios de comunicação de massa em busca de consolidação de protagonismo na sociedade brasileira. Para o autor, as expressões evangélicas têm se mostrado evidentes em diversos campos da vida social brasileira, através de um programa de conquista por visibilidade que vai desde os debates sobre direitos de cidadania até às manifestações de cura da drogadição e manifestações de atletas que expõem sua filiação religiosa nos principais eventos esportivos brasileiros.

\footnotetext{
${ }^{6}$ Anna Virginia Balloussier (2015), "Evangélicos farão marcha contra homofobia na Parada Gay", Folha de São Paulo, 06.06.2015. Consultado a 18.06.2015, em http://www1.folha.uol.com.br/ cotidiano/2015/06/1638621-evangelicos-farao-marcha-contra-homofobia-na-parada-gay.shtml. 7 Tiago Chagas (2015), "Grupo evangélico participa da Parada Gay com críticas a líderes: 'Jesus cura a homofobia”", Gospelmais, 08.06.2015. Consultado a 11.06.2015, em http://noticias.gospelmais. com.br/grupo-evangelico-parada-gay-jesus-cura-homofobia-77177.html.
} 
Destacadamente nas instâncias legislativas municipais, estaduais e federais, houve crescimento da participação de evangélicos e outras filiações religiosas cristãs conservadoras entre os representantes políticos. Para Rodrigues e Fuks (2015), a influência política do movimento evangélico no Brasil é uma temática de relevância, com importante participação numérica na composição das igrejas brasileiras, de atuação na persuasão política dos fiéis através dos mecanismos e ações institucionais, representados por seus pastores e outras lideranças religiosas. Esses parlamentares pertencem a diversos partidos, tanto da direita como da esquerda, apresentando-se como identidade apenas em termos da orientação religiosa, mas não enquanto sigla partidária (Oro, 2003; Machado, 2005).

Em decorrência, a orientação de voto comum dos diversos representantes legislativos desses seguimentos religiosos representados na chamada bancada evangélica no Congresso Nacional não se dá em todas as temáticas, à exceção daquelas relacionadas à diversidade sexual e gênero, em que a defesa da cristandade alinha e une esses parlamentares tanto nos discursos como nos sufrágios, promovendo iniciativas na construção de leis que regulamentam a proibição de casamentos entre pessoas do mesmo sexo e a proibição do aborto no Brasil, e outras como a implementação da alcunhada 'cura gay', em que permitiria aos psicólogos promoverem ações psicoterapêuticas para mudanças na orientação sexual dos indivíduos, contrariando a decisão do Conselho Federal de Psicologia brasileiro (Natividade, 2006; Machado, 2012).

No mesmo domingo em que ocorreu a 19. ${ }^{a}$ Parada, o Deputado Federal Marco Feliciano, que é pastor evangélico, publicou uma manifestação - por meio de seu perfil social no site Facebook ${ }^{8}$ - com um discurso combativo e exclusivamente focado na performance da atriz Viviany Beleboni, desconsiderando qualquer outra manifestação no evento, inclusive dos religiosos do movimento Jesus cura a Homofobia (JCH). O deputado afirmou que os participantes da parada são ativistas pagos com recurso público, que houve desrespeito à fé cristã e que os movimentos tais como a Parada são formas de expressão em relação às quais os grupos envolvidos acreditam ter um direito à liberdade maior do que o dos cristãos. Na publicação virtual, o político pastor conclamou os cristãos e seus líderes religiosos a se mobilizarem contra o que ele chama de cristofobia, aludindo a que as expressões dos movimentos sociais se caracterizam como perseguição religiosa, além de serem contrárias à instituição familiar e à moralidade.

\footnotetext{
${ }_{8}^{8}$ Marcos Feliciano (2015), "Pastor Feliciano comenta sobre a Parada Gay". Consultado a 16.06.2015, em https://www.youtube.com/watch?v=NWVp8mmgoF8.
} 
Decorrente do panorama apresentado, o presente artigo se propõe a discutir as disputas envolvidas no campo de gênero e suas implicações políticas a partir dos discursos das expressões cristãs brasileiras, na mídia e nas redes sociais, perante as repercussões da 19. ${ }^{a}$ Parada do orgulho LGBT de São Paulo, utilizando-se dos aportes da teoria social de Pierre Bourdieu.

\section{Sexualidade, gênero e as relações de poder como construções sociais}

Nas últimas décadas do século Xx ocorreram grandes transformações na ordem social e na intimidade dos indivíduos na sociedade ocidental, particularmente no que Giddens (1993) alerta sobre os questionamentos recorrentes em relação às normas sociais, às políticas, o que é de domínio público e ao âmbito privado da identidade, da identidade sexual (e de gênero) e ao controle exercido pelo social frente a essas questões íntimas. Para Giddens (ibidem: 25), as disputas na temática de gênero encaminham ao entendimento de que se trata de "[...] algo que cada um de nós 'tem', ou cultiva, não mais uma condição natural que um indivíduo aceita como um estado de coisas preestabelecido”.

Judith Butler afirma que os gêneros não têm existência em si, não são naturais, essenciais ou intrínsecos $(2001 ; 2003)$. Ao contrário, são constituídos como resultado da performatividade de gênero, ou seja, são modos construídos socialmente a partir de repetições específicas e esperadas em determinados contextos e que, por sua constante reapresentação, ganham a impressão de naturalidade. Para a autora, os aspectos biológicos que demarcam a diferença sexual são insuficientes para afirmar a constituição do "ser homem" e do "ser mulher" como essencialmente diferente. Segundo a autora, "O gênero não deve ser meramente concebido como a inscrição cultural de significado num sexo previamente dado [...]; tem de designar também o aparato mesmo de produção mediante o qual os próprios sexos são estabelecidos." (Butler, 2003: 25).

Há a reiteração da atribuição social de características distintas a estas diferenças biológicas observáveis, constituindo um campo de expectativas acerca daquilo que será considerado como próprio do homem e/ou da mulher. Estas expectativas constituem um conjunto de normas sociais que regulam as possibilidades aceitáveis frente à performatividade de gênero e que lhes oferece uma inteligibilidade enquanto masculinas ou femininas. Neste sentido, a autora afirma que os efeitos performativos de gênero são reafirmações de modos coletivos de ser, e não expressões de um suposto sujeito autônomo e livre - por isso sua preferência pelo termo performatividade. Nas palavras de Butler, "A performatividade 
não é, assim, um ato singular, pois ela é sempre uma reiteração de uma norma ou conjunto de normas" (Butler, 2001: 167).

A partir da naturalização dos gêneros, construiu-se socialmente a ideia de que os seres se dividem de modo binário, ou seja, entre homens ou mulheres, instituindo uma relação de coerência e linha de continuidade entre o sexo biológico, o gênero, a prática sexual e o desejo. Produz-se e se legitima, portanto, uma matriz heterossexual por meio de discursos que prescrevem a identificação biológica de cada ser enquanto macho ou fêmea, portanto homem ou mulher e consequentemente com desejos e práticas sexuais orientados para o sexo oposto. O que escapa desse binarismo é descrito como abjeto e repreendido socialmente (Butler, 2003).

Nesse sentido, falar de gênero e sexualidade é falar de disputas por hegemonia e, portanto, das relações de poder nos grupos sociais. As obras de Pierre Bourdieu investigam diversos aspectos da dominação, em uma perspectiva interessante para a análise do poder que se distancia das abordagens economicistas, particularmente nos esquemas analíticos do funcionamento de grupos. Pensar as construções sociais do dispositivo compulsório heterossexual e aquilo que confere a um grupo privilégios e poder torna-se, então, passível pelo arcabouço teórico-social desenvolvido por Bourdieu.

Bourdieu afirma que o poder na sociedade não deve ser entendido apenas como relacionado à concentração do capital econômico, mas também àquilo que os dominantes estabelecem como os modos desejáveis e moralmente preferíveis, tal como Butler destaca ao analisar o dispositivo compulsório heterossexual. Bourdieu defende que processos e formas de operação simbólica procedem de transformação das arbitrariedades culturais historicamente construídas em naturais, ou seja, constituindo determinada doxa, a lógica indiscutível dos dominantes. Valendo-se dessa perspectiva, a heterossexualidade será uma doxa na sociedade brasileira.

Os esquemas analíticos de funcionamento aceitos pelos dominantes de determinado grupo social, em uma constante dinâmica para a manutenção do status quo, baseiam-se em uma série de desigualdades e distinções dentro dos vários grupos e entre si, nos quais as ideias e as regras são muitas vezes mais importantes que a própria economia, a exemplo das moralidades que recaem na interpretação das pessoas LGBT como desviantes e no consequente medo, por exemplo, de coerção física corretiva/punitiva para essas pessoas, assim para os comportamentos que remetam a elas.

O elemento fundamental para compreensão dos fundamentos sociais das distâncias sociais, em Bourdieu, refere-se a essas dimensões ignoradas do poder, de difícil reconhecimento a priori, justamente por ser o próprio 
fundamento do poder. Por ser fundamento, está presente na determinação social do arbitrário como lógica e como mecanismo de integração social, se definindo como consensus e os atributos da moral que os permeia, assim como a própria definição de seus critérios de funcionamento, como a figura das entidades que os determinam, e especialmente a distribuição de poderes entre os que obedecem e os que comandam - que tem por função estabelecer o nomos.?

Um aspecto fundamental para Bourdieu em termos das características do poder é seu caráter oculto, inaparente (2007). Nesse sentido, essas relações constroem-se socialmente através de ideias coerentes com a lógica dos dominadores, que trazem um caráter de naturalização às relações díspares de distribuição de poder, justificando-as. Nas palavras de Bourdieu, trata-se de "O Poder de constituir o dado pela enunciação". Haverá, assim, uma distribuição determinada de possibilidades entre o grupo acumulando valores e manifestações objetivas, mas decorrentes da organização interna que acontecerá primeiro em caráter simbólico, a exemplo dos processos envolvidos nas demarcações da heterossexualidade como compulsória.

Segundo Bourdieu, grupos sociais hegemônicos, seja qual for a sua natureza, exercem e garantem a reprodução de sua posição social e da coesão que mantém a sociedade através de um modus operandi, empregando coerção aos grupos dominados, por processos ideológicos, físicos e econômicos, a partir da economia das trocas simbólicas e das posições sociais de quem pode dar e quem precisa receber, tanto em aspectos objetivos como nos subjetivos das relações sociais (Bourdieu, 2011).

Ao analisar a questão de gênero na sociedade, Bourdieu refere-se à dominação masculina, que torna uma diferença anatômica - com destaque para os órgãos sexuais - como a justificativa para diferenças de gênero com caráter natural, o que se trata de uma leitura socialmente construída pelos homens dominantes. Bourdieu ressalta o aspecto mágico que essa forma naturalizada dá aos homens, como indiscutível, mesmo porque em cima da obviedade desenvolvem-se maneiras sistemáticas de comprovar a lógica dessa arbitrariedade - muitas vezes, não se questionam como tal por que detêm prestígio no campo simbólico, constituindo-se enquanto

\footnotetext{
${ }^{9} \mathrm{O}$ termo nomos refere-se aos princípios fundamentais de divisões e visibilidades presentes nos campos, no sentido da organização de leis que regem as práticas e as experiências, tanto quanto a visibilidade da inscrição de determinado agente ao se reconhece e ser reconhecido por meio de suas práticas particulares. O poder se constituirá e manifestará através de sistemas simbólicos que organizarão as formas de funcionamento dos grupos, através de "instrumentos de imposição ou de legitimação da dominação" (Bourdieu, 2007: 16) por sistemas de classificação legitimados como nomos e, portanto, aceitos pelos membros dominados.
} 
o topo da hierarquia de uma ordem social que imprime nos corpos e nas mentes uma realidade indissociável do corpo enquanto sexual (Bourdieu, 2014a: 24).

Nesse processo propriamente de economia dos bens simbólicos, que produzem as crenças, as disputas por posições de autoridade e das mensagens consideradas como verdades se constituem como lutas por legitimidade entre aqueles que desejam ser porta-vozes de seus grupos, representantes dos dominantes frente aos dominados (Bourdieu, 2014b).

O babitus ${ }^{10}$ funciona então como norma naturalizada e, particularmente nas questões referentes aos gêneros e sexualidades, existe uma imposição de práticas heterossexuais tomadas como legítimas para os grupos sociais, conceito que tem relevância para o presente artigo. Esse processo é dinâmico, mediatizado nas relações que "[...] se fazem, se desfazem e se refazem na e pela interação entre as pessoas [...] tem a opacidade e a permanência das coisas e escapam à influência da consciência e do poder individuais" (Bourdieu, 2014b: 193).

Questionar os padrões da heteronormatividade é, de certa forma, questionar as condições sociais que permitem e legitimam o domínio sobre os corpos e sobre os sexos, sendo importante o entendimento dos fenômenos da vergonha (corporal e cultural) frente ao modelo de correção. É, portanto um campo de lutas políticas, em cujo princípio da disputa entre os dominantes pela apropriação da "energia social acumulada" (Bourdieu, 2014a: 25) em relação à instituição das verdades, tais como naturalidade da heterossexualidade (Bourdieu, 2014b) em concorrência com a (im)possibilidade de experiências socialmente aceitas para pessoas LGBT.

Defender a família tradicional e heterossexual traduz, então, estabelecer uma mensagem que legitime os representantes políticos frente a determinado público que tem esse habitus como natural, assim como demarcar publicamente uma posição contra seus antagonistas e oponentes, fazendo pensar na importância da repercussão midiática de eventos como a referida Parada nas disputas políticas entre as interpretações religiosas sobre a sexualidade e a luta dos movimentos sociais LGBT.

\footnotetext{
${ }^{10}$ O conceito de habitus é definido por Bourdieu (2009: 87), em sua condição de produto do mundo prático e aquilo que engendra sua reprodução, sendo "[...] sistemas de disposições duráveis e transponíveis, estruturas estruturadas predispostas a funcionar como estruturas estruturantes, ou seja, como princípios geradores e organizadores de práticas e de representações que podem ser objetivamente adaptadas ao seu objetivo sem supor a intenção consciente de fins e o domínio expresso das operações necessárias para alcançá-los, objetivamente "reguladas" e "regulares" sem em nada ser o produto da obediência a algumas regras e, sendo tudo isso, coletivamente orquestradas sem ser o produto da ação organizadora de um maestro".
} 
Para Bourdieu (2014a) será fundamental que cada concorrente convença determinado público sobre necessidades que somente ele possa prover, ou de maneira mais adequada, o uso das forças políticas que dispõe como representante frente ao que oferecem os demais concorrentes. Segundo Bourdieu (ibidem), a discordância e a concordância de determinado público em relação aos discursos proferidos pelo representante de seu campo referem-se à influência que possui sobre o público, "[...] na medida em que estes the atribuem tal poder porque estão estruturalmente afinados com ele em sua visão do mundo social, suas preferências e todo seu habitus" (ibidem: 57). Retorna assim à ideia da importância de manifestações públicas perante eventos de temas polêmicos, como pode ser caracterizado pelas disputas que existem em relação aos direitos da população LGBT na política brasileira.

\section{O rebanho e a construção do inimigo}

No dia 7 de junho de 2015, por ocasião da 19. . Parada do orgulho LGBT, foi criada no Facebook a comunidade "Jesus cura a homofobia" (JCH). Promovida como evento na rede social com a definição dos organizadores de "Ato promovido por cristãos evangélicos e católicos contra a intolerância, desrespeito e violência praticadas em relação à comunidade LGBT", ${ }^{11}$ que atingiu 12 mil curtidas $^{12}$ na referida rede social.

No lançamento virtual da comunidade, os administradores veicularam um "Manifesto de evangélicos, católicos, e outros religiosos solidários às LGBTIs (São Paulo, 07.06.2015)", no qual declaram o combate ao ódio, ao fundamentalismo e ao que chamam de "cultura do medo à diferença" proliferado por alguns líderes religiosos brasileiros. Em diversas postagens dos administradores fica patente a divergência em relação às lideranças, que o grupo caracteriza como problemática, por uma interpretação do cristianismo que vai diametralmente contra o princípio fundamental dessa religião.

A análise das postagens e comentários da comunidade virtual aponta o caráter de movimento espontâneo de fiéis, sem vinculação a qualquer liderança religiosa cristã e/ou apoio institucional, congregando diferentes denominações pentecostais e católicas. O teor das mensagens veiculadas pelos administradores da comunidade fundamenta-se e defende uma interpretação dos princípios cristãos baseados na inclusão de todos os seres humanos, independentemente de suas orientações sexuais, focando no

\footnotetext{
${ }^{11}$ Consultado a 14.07.2015 em https://www.facebook.com/pages/Jesus-Cura-a-Homofobia/825 017950923171 ? ref $=$ ts\&fref $=$ ts.

12 Ato voluntário dos participantes de determinada rede social, em que indica a aprovação por específica mensagem veiculada na referida rede. O termo curtir provém de adaptação na tradução do original em inglês "like" ("gostei").
} 
princípio fundamental do cristianismo que, para os organizadores, é o "amor ao próximo".

A iniciativa JCH gerou reações no meio cristão, com expressões no interior da comunidade virtual. Fiéis se manifestaram contrários à iniciativa, apelando para a interpretação que patologiza e discrimina as pessoas LGBT, em consonância com o discurso dos líderes religiosos combatidos nas mensagens dos organizadores da comunidade. O conteúdo discursivo foi pautado em contradizer a inclusão preconizada pelo movimento JCH e na reprodução da perspectiva moral e heteronormativa, reafirmando as considerações de Natividade e Oliveira (2013: 144), para quem a reação discursiva das pessoas religiosas conservadoras frente à ampliação dos direitos cidadãos dos homossexuais é uma forma de afronta, violação de direitos e liberdades ou mesmo perseguição aos religiosos.

Em alguns comentários os organizadores foram acusados de blasfêmia e de ferirem a sacralidade tanto do cristianismo como de seus representantes, e de incitarem posturas rebeldes com relação aos porta-vozes oficiais das instituições religiosas. Para esses fiéis, qualquer manifestação de criticidade ou questionamento é considerado como pecado, independente das implicações do princípio de "amor ao próximo". A esse respeito, Natividade e Oliveira (2013) analisam que existe uma disputa pelos significados entre os religiosos, mas que a posição de luta política contra as pessoas LGBT “[...] não diz respeito apenas à ausência de reconhecimento, mas a mecanismos de exercício do poder, sustentados por expectativas sociais heterosexistas e por certas convenções sociais" (ibidem: 25).

Por outra abordagem da questão, as práticas e os discursos dos agentes são fundamentais para o entendimento das posições ocupadas nos diferentes campos de conflitos pela legítima visão do mundo, na ocupação da "hierarquia da legitimidade" segundo Bourdieu (2014b: 141), nos processos sociais da produção de crenças e de bens simbólicos. Nesse contexto, a representação da verdade e do belo ocasionará manifestações políticas na busca da imposição de definições para determinada realidade social, tal como pode ser observado entre os fiéis participantes JCH e aos demais fiéis.

O discurso de proteção da moral e dos bons costumes oriundos dos seguimentos religiosos apresenta um conteúdo não explícito de interesses políticos, na medida em que, "A aversão à expressão pública de afeto entre pessoas LGBT, por exemplo, poderia ser interpretada como objeção política à visibilidade dessas minorias, associada às disposições conservadoras tocantes à moral sexual" (Natividade e Oliveira, 2013: 78).

O alinhamento e desalinhamento para com o discurso dominante das lideranças evangélicas foi o palco da disputa para se definir qual dos grupos 
representa a verdadeira mensagem cristã, relembrando o que Bourdieu afirma ao analisar a importância da história dos discursos na constituição de um campo, "[...] a luta pelo monopólio da imposição das categorias de percepção legítima; é a própria luta que faz a história do campo; é pela luta que ele se temporiza" (Bourdieu, 2014a: 88).

O mundo social não se dá no vazio, segundo Bourdieu (2011). A cooperação e o conflito vão se constituir como relações de tensão sobre as quais importa e refere-se "[...] a posição ocupada no espaço social, isto é, na estrutura de distribuição de diferentes tipos de capital que também são armas, comanda as representações e as tomadas de posição nas lutas para conservá-lo ou transformá-lo" (ibidem: 27). Na concepção de Natividade e Oliveira (2013: 75) as religiões são instituições em que os líderes se utilizam de técnicas pastorais nos laços sociais entre os fiéis e a/na sociedade, mas que também têm efeitos nas práticas e influência no campo político. Nesse sentido, os autores ressaltam o papel das lideranças pastorais como "paladinos e porta-vozes" que defendem um discurso valorativo construído a partir da heterossexualidade compulsória, tal como Butler alcunhou o termo.

Segundo Bourdieu (2011), a constituição de grupos unidos demanda trabalho simbólico que consagre termos, pessoas, manifestações públicas, entre outras formas de expressão, cujo sucesso depende dos agentes sociais de interesse, tal como pode ser observado em termos das posições públicas dos pastores, dos fiéis e das pessoas LGBT que disputam estabelecimento na sociedade brasileira. Nesse campo, a constituição das representações que os grupos têm de si mesmos exige perpétuo trabalho, "[...] pelo qual os agentes produzem e reproduzem, na e pela ficção, a aparência ao menos de conformidade à verdade ideal do grupo, a seu ideal de verdade" (ibidem: 218), conceito que pode ser caracterizado na atuação do referido deputado e pastor no contexto aqui investigado.

Expressão paralela à da comunidade $\mathrm{JCH}$, o teor discursivo assumido pelo referido deputado Feliciano frente à performance de Beleboni apresentou certo caráter de disputa valorativa e de capacidade de mobilização de energia simbólica no processo social de produção de crença, o que é coerente com a ideia de Bourdieu (2014b: 162) de que "o poder das palavras não reside nas próprias palavras, mas nas condições que dão poder às palavras criando a crença coletiva, ou seja, o desconhecimento coletivo da criação de valor que se consuma através de determinado uso das palavras".

Em entrevista concedida à apresentadora Luciana Gimenez,,$^{13}$ o deputado reafirma que não se manifestou apenas pela performance da atriz,

$\overline{13}$ Consultado a 19.06.2015, em https://www.youtube.com/watch?v=_JCdrYUw06Y. 
mas contra todos os movimentos que questionem as normas e padrões religiosos cristãos, como pode ser observado em seu julgamento moral, ao proferir que "Ele (Jesus) morreu exatamente por aquilo que ela faz. Ele morreu pelos pecadores, pelas pessoas que cometem algum tipo de crime e precisavam ser exoneradas do céu”. Uma preocupação reincidente na entrevista do deputado é a repercussão na imprensa nacional e internacional da performance, que para ele fere as verdades do texto sagrado utilizado na religião cristã e que condena todo ato homossexual.

A despeito do discurso explícito do deputado em defesa da moral cristã, as considerações e implicações no campo político, principalmente no que se refere a chamada bancada evangélica, suscitam reflexões tais como as de Bourdieu (2014b) sobre a produção da crença como fundamento da economia dos bens simbólicos cujos empreendimentos simbólicos dos produtores e vendedores dos bens culturais dissimulam os interesses de ganho de capital simbólico e econômico através de estratégias de sua denegação. Um aspecto que chama a atenção é a totalização da experiência LGBT no conceito de "homossexuais" no conteúdo das falas de Feliciano, que desconsidera a existência de qualquer outra identidade de gênero que não seja heterossexual, gay e lésbica, a despeito de Beleboni se definir como travesti.

Conforme Natividade e Oliveira (2013) há uma construção histórica dos homossexuais como personagens de ameaça, representantes da impureza, da anormalidade e da doença, no que os autores chamam de "sexologia religiosa”, em que existem verdadeiros tratados sobre práticas sexuais admitidas e práticas sexuais proibidas, valendo-se do princípio de que existe certa essência da vontade de Deus e a religião, dogmas que construídos a partir de uma ordem tomada como natural para o mundo e os seres.

Os autores ainda apresentam que essa interpretação promove um dispositivo que, em sua operação, transforma os militantes LGBT em agentes de forças ocultas contra a natureza e o bem, e o ato de ir contra os direitos dessas pessoas se constrói como verdadeira cruzada moral, em que a política se insere em "cosmologia da batalha espiritual" (ibidem: 96).

Um exemplo desses conceitos é o discurso do pastor, que explicita a defesa dos valores da religião e dos cristãos frente a uma verdadeira guerra contra os representantes de um inimigo demoníaco, sem mencionar em nenhum momento discursos divergentes internos ao meio cristão tais como o movimento JCH, e reivindica a legitimidade como autoridade em defesa da cristandade na medida em que outros líderes cristãos não se posicionaram no tocante à performance de Beleboni. Por efeito, a postura discursiva do Pastor Feliciano o coloca na posição dos "porta-vozes de valores universais, 
bastiões da moralidade, conjugando percepções negativas da diversidade sexual a uma atuação em oposição ao seu reconhecimento, compreendido como ameaça" (ibidem: 81).

As repercussões da 19. ${ }^{a}$ Parada podem, assim, exemplificar a importância da construção do movimento LGBT como inimigo político dos seguimentos evangélicos brasileiros, constituído e legitimado através de táticas plurais, polimorfas e incidentes através de heterogeneidade de práticas e do controle da sexualidade (Natividade e Oliveira, 2013), mas também como um importante espaço para a conquista por autoridade dos deputados evangélicos frente ao potencial de crédito que pode ser oportunizado pelas pessoas que representam politicamente (Bourdieu, 2014b).

Há que se ressaltar que a Parada do orgulho LGBT de São Paulo é alvo de destaque todos os anos na mídia nacional e internacional, podendo ser entendido, a partir da ação do deputado Feliciano, como certa disputa de quem representa as opiniões e pelas imagens sobre o bem e o mal difundidas pelos meios de comunicação em massa, importante na arena pública de disputas políticas. Conforme Bourdieu (ibidem: 163) "na produção de bens simbólicos, as instituições aparentemente encarregadas de sua circulação fazem parte integrante do aparelho de produção que deve produzir, não só o produto, mas também a crença no valor do produto".

Os potenciais de repercussão midiática e política das paradas do orgulho LGBT se configuram como espaço de disputa por posição e influência social no Brasil haja vista para as manifestações tanto do JCH quanto dos fiéis contrários ao movimento, e, também, da figura do pastor e deputado Marco Feliciano frente à performance de Beleboni.

Para Pace (2009), a religião é por si uma instituição em que a comunicação é característica, uma vez que se trata da utilização de narrativas e rituais, hermenêuticos ou não, em que se criam, limitam e excluem sentidos simbólicos dos indivíduos e grupos sociais, de forma que a palavra representada pelos líderes religiosos tem condições históricas e sociais para construir realidades. Nesse sentido, as opiniões e posições tomadas pelas instituições religiosas têm potencial de direcionamento de massas de indivíduos, sendo o aspecto midiático fundamental para o entendimento desse processo.

Assim, Natividade e Oliveira (2013) destacam que a produção de discursos em que a diversidade sexual é apresentada como negativa e perigosa à sociedade são fundamentais, dado que as instituições e as redes de agentes da heteronormatividade compulsória se sustentam através do antagonismo aos LGBT que, portanto, não devem receber proteção do Estado na medida em que são pecadores, anormais, abjetos e doentes. 


\section{Reverberações no rebanho}

Há que questionar, no panorama apresentado, por que o ataque do deputado e líder religioso foi dirigido exclusivamente à performance da atriz e não mencionou, em momento algum, o coletivo de cristãos que apresentam uma interpretação diferente da que ele representa em relação ao texto sagrado de sua religião. Ao que parece, a despeito da importância no questionamento dos fundamentos da fé religiosa que esse coletivo JCH poderia incitar, a iniciativa não teve a repercussão que a performance da atriz despertou na mídia, principalmente em termos de amplitude nacional e internacional. Por outro lado, invisibilizar o discurso do movimento JCH pode também se relacionar ao desejo de não reconhecer em seu discurso outras possibilidades de ser cristão - de modo a legitimar-se como seu único porta-voz, uma vez que o campo do poder é um espaço com efeito em diferentes campos, tais como o econômico e o cultural, tal como concebido por Bourdieu.

Em relação à performance de Viviany Beleboni por outras expressões cristãs não evangélicas, destacou-se na mídia a nota da Confederação Nacional dos Bispos do Brasil, escrita pelo Cardeal e Arcebispo do Estado de São Paulo, Dom Odilo Scherer, que tomou uma posição de advertência com relação à banalização do símbolo da cruz e ao sentimento que a ação poderia ter desencadeado nos cristãos. No entanto, a mensagem foi silenciosa em relação à posição da Igreja Católica quanto à população LGBT.

Paralelamente, na rede social Facebook, alguns padres católicos, como Julio Lancelotti, ${ }^{14}$ declararam a relevância da ação de Beleboni, assim como o entendimento de que não houve ataque à religião, mas sim denúncia de sofrimento por parte da população LGBT. Quase sem repercussão na mídia, com divulgação em blogues e páginas de menor alcance nacional, no dia 29 de junho de 2015 o referido padre e o pastor evangélico José Barbosa Júnior promoveram um ato de apoio à performance de Beleboni, lavando seus pés tal como as manifestações cristãs correlatas. O pastor declarou "Fizemos isso como um ato de desagravo, pedido de perdão pelas muitas crucificações que as pessoas LGBT sofrem no Brasil e como atitude de serviço, porque entendemos que os cristãos devem servir aos oprimidos, excluídos e aos que sofrem toda sorte de preconceitos". ${ }^{15} \mathrm{O}$ padre Lancellotti afirmou que o ato é cristão, ressaltando que o Papa Francisco recebeu uma transexual em sua visita à Espanha em 2015.

\footnotetext{
${ }^{14}$ Consultado a 10.07.2015, em https://www.facebook.com/profile.php?id=100009727774798 \&fref $=$ ts.

${ }_{15}$ Consultado a 14.07.2015, em http://blogs.odia.ig.com.br/lgbt/2015/06/29/padre-e-pastor -lavam-pes-de-atriz-crucificada-na-parada-lgbt/.
} 
Meio de manifestação e de manutenção dessa ordem, o discurso dominante heterossexual compulsório é estruturado e estruturante, operando "[...] por meio da imposição mascarada (logo, ignorada como tal) de sistemas de classificação e de estruturas mentais objetivamente ajustadas às estruturas sociais" (Bourdieu, 2007: 13). O que nos leva ao encontro do "paradoxo da doxa", no qual os dominados aceitam sua condição e a reproduzem, não apenas por não a questionar, mas também por defender a sua lógica. Por efeito, o conservadorismo dos representados, moldado pelo discurso dos representantes legislativos, irá contrapor às expressões como a de Beleboni que, ressaltamos, refere-se a uma performance artística que denunciou as mortes das pessoas LGBT, localizando-as como ameaça aos valores naturais e cristãos, demandando a cruzada espiritual e política alardeada pelos representantes legislativos da bancada evangélica brasileira.

\section{Considerações finais}

Conforme analisado, as disputas políticas entorno das expressões de grupos como as pessoas LGBT, na performance de Beleboni e dos cristãos, com a iniciativa JCH frente aos representantes legislativos contrários a causas LGBT, tais como o Pastor Deputado Marco Feliciano, são indicativas do modo como as relações de gênero são importantes instâncias com implicações políticas.

Levar em considerações as manifestações e as expressões aqui apresentadas pode se constituir como uma abordagem possível para a compreensão de tensões existentes entre os grupos religiosos e seus representantes políticos, frente à reivindicação por direitos apresentada pelos Movimentos Sociais LGBT, panorama que implica tanto em disputa pela conquista de espaços sociais, como em produção de discursividades na definição dos campos político e midiático. Cabe considerar que cada ator aqui retratado representa na arena política da diversidade sexual e do gênero certos enunciados de caráter performativo, tal como analisado no presente artigo. Os atos produzidos, seja pelo movimento JCH, pelos fiéis cristãos que discordaram do movimento, por Viviany Beleboni ou pelo Deputado Marco Feliciano ocasionam efeitos e disputas em termos sociais, defendendo certas inteligibilidades e modos de ser, no questionamento ou na manutenção do status quo da heterossexualidade compulsória.

O aporte teórico utilizado na intenção de analisar os acontecimentos publicitados sobre a 19. ${ }^{\text {a }}$ Parada mostrou-se fundamental, pois permitiu investigar alguns elementos de certa tessitura das disputas políticas, imagéticas e discursivas do fenômeno. Nesse sentido, a teoria bourdiesiana foi fundamental, visto que não se trata de um fenômeno apenas religioso, ou militante, ou mesmo que se refira às questões de gênero em suas práticas cotidianas. Antes, todas 
essas dimensões estiveram implicadas na arena política e no contexto histórico de crescimento da bancada evangélica e de seus inimigos construídos. Paralelamente, o avanço dos direitos da minoria política que constituem as pessoas LGBT no Brasil também pode ser analisado.

Na prática, dentro dos pressupostos elucidados no presente artigo, mais do que apenas o aspecto discursivo e/ou midiático, o fenômeno fala sobre a cumplicidade cotidiana de pessoas aos discursos de seus líderes e representantes políticos, a despeito da explicação/justificativa de caráter religioso. Esses processos ocorrem na medida em que os grupos apresentam respostas socialmente aprendidas no transcorrer da história individual dos indivíduos, tanto na coletividade como na família através das experiências do correto e do incorreto para determinada sociedade, constituindo-se como babitus conforme analisado.

A argumentação empregada no presente artigo referiu-se à repercussão na mídia da performance de Beleboni, contrapondo ao movimento cristão JCH. No entanto, há uma outra perspectiva que demanda novas investigações: Viviany Beleboni teria desafiado as legitimidades e as lideranças individuais dos representantes legislativos da bancada evangélica justamente por ser ela um indivíduo com um discurso que se contrapõe ao discurso massificador e pastoral? Por que uma ação coletiva de indivíduos no seio do cristianismo como JCH, não seria alvo de qualquer ataque desses mesmos representantes legislativos, já que ambas foram divulgadas nas mídias e redes sociais?

As reflexões trazidas pela análise do presente artigo incidem diretamente sobre o babitus e o campo político a partir dos discursos e posições políticas/ /midiáticas dos deputados da bancada evangélica. É interessante notar que outras expressões de divergência com a heteronormatividade compulsória não provocaram reações semelhantes dos referidos deputados.

\section{Referências bibliográficas}

Bourdieu, Pierre (2007), O poder simbólico. Rio de Janeiro: Bertrand Brasil.

Bourdieu, Pierre (2009), O senso prático. Petrópolis, RJ: Vozes.

Bourdieu, Pierre (2011), Razões práticas: sobre a teoria da ação. São Paulo: Papirus.

Bourdieu, Pierre (2014a), A dominação masculina: a condição feminina e a violência simbólica. Rio de Janeiro: Bestbolso.

Bourdieu, Pierre (2014b), A produção da crença: contribuição para uma economia dos bens simbólicos. Porto Alegre: Zouk.

Butler, Judith (2001), "Corpos que pesam: sobre os limites discursivos do 'sexo'", in Guaraci Louro (org.), O corpo educado: pedagogias da sexualidade. Belo Horizonte: Autêntica, 151-172. 
Butler, Judith (2003), Problemas de gênero: Feminismo e subversão da identidade. Rio de Janeiro: Civilização Brasileira.

Carvalho, Carlos Alberto de (2013), Jornalismo, bomofobia e relações de gênero. Curitiba: Ed. Appris.

Giddens, Anthony (1993), As transformações da intimidade: sexualidade, amor e erotismo nas sociedades modernas. São Paulo: Ed. UNESP.

Giumbelli, Emerson (2014), Símbolos religiosos em controvérsia. São Paulo: Terceiro Nome.

Instituto Brasileiro de Geografia e Estatística (2012), Censo demográfico 2010: características gerais da população, religião e pessoas com deficiências. Rio de Janeiro: IBGE.

Machado, Maria das Dores Campos (2005), "Representações e relações de gênero nos grupos pentecostais”, Revista Estudos Feministas, 13(2), 387-396.

Machado, Maria das Dores Campos (2012), "Religião, cultura e política”, Religião e Sociedade, 32(2), 29-56.

Natividade, Marcelo (2006), "Homossexualidade, gênero e cura em perspectivas pastorais evangélicas”, Revista Brasileira de Ciências Sociais, 21(61), 115-132.

Natividade, Marcelo; Oliveira, Leandro de (2013), As novas guerras sexuais: diferenças, poder religioso e identidades LGBT no Brasil. Rio de Janeiro: Garamond.

Oro, Ari Pedro (2003), "A política da Igreja Universal e seus reflexos nos campos religioso e político brasileiros”, Revista Brasileira de Ciências Sociais, 18(53), 53-69.

Pace, Enzo (2009), "Narrar a Deus: a religião como meio de comunicação", Revista Brasileira de Ciências Sociais, 24(70), 09-15.

Rodrigues, Guilherme Alberto; Fuks, Mário (2015), "Grupos sociais e preferência política: o voto evangélico no Brasil”, Revista Brasileira de Ciências Sociais, 30(87), 115-128.

Artigo recebido a 30.07.2015

Aprovado para publicação a 06.05.2016

\section{Rodrigo Otávio Moretti-Pires}

Centro de Ciências da Saúde, Universidade Federal de Santa Catarina Campus Universitário Trindade, Florianópolis (SC), CEP 88040-001, Brasil

Contato: rodrigo.moretti@ufsc.br

\section{Zeno Carlos Tesser Júnior}

Centro de Ciências da Saúde, Universidade Federal de Santa Catarina Campus Universitário Trindade, Florianópolis (SC), CEP 88040-001, Brasil Contato: zenotj@@gmail.com 


\author{
Marcelo Vieira \\ Centro de Ciências da Saúde, Universidade Federal de Santa Catarina \\ Campus Universitário Trindade, Florianópolis (SC), CEP 88040-001, Brasil \\ Contato: marcelovieirantr@gmail.com
}

\title{
Murilo dos Santos Moscheta
}

Departamento de Psicologia, Universidade Estadual de Maringá

Avenida Colombo, 5790, Jardim Universitário, Maringá (PR), CEP 87020 -900, Bloco 118, Brasil

Contato: murilomoscheta@me.com

\section{Shepherds, Lost Sheep and Disputes over the Flock: Trans-Crucifixion at the São Paulo LGBT Pride Parade, 2015}

The LGBT Pride Parade in São Paulo (Brazil) is one of biggest of its kind in the world. Its 19th edition, which took place in July 2015, was marked by two events that received extensive media coverage: a crucified transgender woman denouncing gender phobias and violence against LGBT people, and a group of Christians bearing the slogan "Jesus cures homophobia". These episodes triggered significant political debates and disputes, since the fight against LGBT civil rights is an important item on the agenda of Brazilian evangelical politicians, who make up one of the most important political forces in the Brazil's Chamber of Deputies: the evangelical bench. This article discusses gender disputes and their political implications in the wake of the 19th LGBT Pride Parade in São Paulo, using Pierre Bourdieu's social theory.

Keywords: gender; homophobia; LGBT movement; politics; religion; sexual diversity.

\section{Bergers, brebis égarées et les disputes à cause du troupeau: sur la transcrucifixion durant la Marche des fiertés (Gay pride) LGBT de São Paulo en 2015}

La Marche des fiertés LGBT de São Paulo (Brésil) est l'un des évènements mondiaux les plus importants en la matière. En juillet 2015 eut lieu la 19 ème édition de l'évènement et deux manifestations méritèrent l'attention toute particulière des moyens de communication de masses: un travesti crucifié dénonçant les phobies de genre et les violences perpétrées contre des personnes LGBT et un groupe de chrétiens organisés sous le slogan "Jésus guérit l'homophobie". Ces expressions ont promus des débats et des échauffourées politiques importants, puisque le combat contre les droits civils de personnes LGBT est un point majeur des politiques évangéliques brésiliens qui composent une des représentations politiques les plus importantes de la Chambre Fédérale des Députés: le groupe évangélique. Le présent article se penche sur les disputes engagées dans le domaine de genre et sur leurs implications politiques face à la $19^{\text {ème }}$ Marche des fiertés LGBT de São Paulo, en utilisant des apports de la théorie sociale de Pierre Bourdieu.

Mots-clés: diversité sexuelle; genre; homophobie; mouvement LGBT; politique; religion. 